\title{
Comportamento de estacas escavadas compostas de solo- cimento e resíduo de beneficiamento de pedras preciosas a partir de provas de carga estática
}

\author{
Behavior of bored piles composed of soil-cement and \\ residue of precious stones based on static load tests
}

\author{
Patrícia Edler \\ Antonio Thomé \\ Carina Silvani \\ Leunir Laudimar Freitas
}

\section{Resumo}

Patrícia Edler

Programa de Pós-Graduação em Engenharia, Infraestrutura e Meio Ambiente

Universidade de Passo Fundo BR 285 km 171, Campus I, São J osé Passo Fundo - RS - Brasil Caixa Postal 611 CEP 99001-970

Tel.: (54) 3116-8203

E-mail: patricia_edler@hotmail.com

Antonio Thomé Programa de Pós-Graduação em Engenharia, Infraestrutura e Meio Ambiente

Universidade de Passo Fundo

E-mail: thome@upf.br

Carina Silvani

Programa de Pós-Graduação em
Engenharia Civil

Programa de Pós-Graduação em
Engenharia Civil do Sul

Rua Osvaldo Aranha, 99, 30 andar,
Centro

Porto Alegre - RS - Brasil

CEP $90035-190$

Tel : (51) 3308-3486

E-mail: carinasilvani@terra.com.br

Leunir Laudimar Freitas

Centro Tecnológico, Faculdade de

Engenharia e Arquitetura,

Universidade de Passo Fundo

E-mail: leunirfreitas@pop.com.br

Recebido em 28/09/11

Aceito em 25/08/12
A

utilização de resíduos e subprodutos industriais na construção civil apresenta-se como uma alternativa efetiva para diminuição do impacto ambiental deste setor. O presente trabalho tem como principal objetivo avaliar a viabilidade do emprego de solo-cimento e resíduo de beneficiamento de pedras preciosas em estacas escavadas (SCR) para utilização em habitação unifamiliar. Inicialmente foi definida uma mistura ótima com os materiais que constituiriam as estacas. A mistura que melhor atendeu as características de resistência e trabalhabilidade foi àquela composta por $50 \%$ de resíduo de beneficiamento de pedras preciosas e $50 \%$ de solo, com $10 \%$ de teor de cimento Portland, em relação a massa seca dos materiais. Para os ensaios de campo foram executadas três estacas escavadas de $0,23 \mathrm{~m}$ de diâmetro e 3 metros de profundidade. Os resultados obtidos através das provas de carga estática foram comparados a resultados de estacas escavadas com mesmas características geométricas e compostas por concreto convencional. $\mathrm{O}$ estudo concluiu que $\mathrm{o}$ emprego da mistura de solo-cimento e resíduo de beneficiamento de pedras preciosas em estacas escavadas moldadas in loco é tecnicamente viável, uma vez que apresentam capacidade de carga semelhante às executadas com concreto convencional. Além disso, a partir da análise de custos, onde se comparou o valor de execução para estacas de concreto e estacas de solo-cimento e resíduo, verificou-se que o custo final de uma estaca escavada produzida com a mistura proposta apresenta uma economia de $38 \%$, se comparado ao custo final de uma estaca escavada composta por concreto convencional.

Palavras-chave: Resíduo industrial. Estacas escavadas. Capacidade de carga.

\section{Abstract}

The use of residues and industrial by-products in construction is an effective alternative for reducing environmental impact of this sector. The aim of this study is to evaluate the feasibility of using soil-cement and residue from precious stones in bored piles for housing construction. The mixture that presented the best strength and workability characteristics consisted of 50\% residues, $50 \%$ soil and $10 \%$ Portland cement (in dry weight of materials). For the field tests, three bored piles measuring $0.23 \mathrm{~m}$ in diameter and 3 meters in depth were executed. The results obtained using static load tests with soil-cement and residue piles were compared with results of bored piles with the same geometrical characteristics and made with conventional concrete. The study concluded that it is technically feasible to use the mixture of soil-cement and the residue of precious stones for bored piles, since the load capacity is similar to that of those performed by conventional concrete. In addition, the cost analysis showed that the final price of a bored pile made with soil-cement and residue is up to 38\% lower than the price of those made with traditional concrete.

Keywords: Industrial waste. Bored piles. Load capacity. 


\section{Introdução}

Uma parte fundamental da discussão sobre sustentabilidade refere-se ao ambiente construído e à atuação da indústria da construção civil. As atividades da construção civil têm grandes impactos sobre o meio ambiente, em função do consumo de recursos naturais ou extração de jazidas; consumo de energia elétrica nas fases de extração, transformação, fabricação, transporte e aplicação; geração de resíduo decorrentes de perdas, desperdício e demolições; bem como desmatamento e alterações no relevo (ÖSTRÖM; BAKENS, 1999; WOOLEY et al., 1997).

Os resíduos e entulhos gerados pelos canteiros de obras transformam o setor da construção civil em um dos principais responsáveis pela poluição do meio ambiente. Entre os resíduos oriundos da construção civil está o solo, que, apesar de ser um componente natural, ao ser descartado após processos de escavação, é abandonado em depósitos clandestinos de entulhos, espaço bastante comum em áreas urbanas (GONZALES; RAMIRES, 2005). Um estudo promovido pelo International Council for Research and Innovation in Building and Construction (CIB), que gerou a "Agenda 21 para a Construção Sustentável", também indica a indústria da construção civil como elemento de grande importância na questão da sustentabilidade. Segundo esse estudo, as construções na União Europeia são responsáveis por mais de $40 \%$ do consumo total de energia, e estima-se que o setor da construção gere aproximadamente $40 \%$ de todo o lixo produzido pelo homem. No Brasil, para 2011, a previsão de crescimento do setor da construção civil foi de 6,6\% (CÂMARA..., 2011). Estima-se que os resíduos da construção civil representam de $41 \%$ a $70 \%$ do total dos resíduos sólidos gerados em áreas urbanas (SCHNEIDER; PHILIPPI JUNIOR, 2004).

A indústria de pedras preciosas é muito importante para a economia do Brasil. Atualmente o Brasil é o maior produtor mundial de ametista e de ágata, com destaque para o estado do Rio Grande do Sul (418 t/mês). Em torno de 130 t/mês são transformadas na região de Soledade, RS, produzindo-se mais de 6.000 peças/mês. No processo de transformação são gerados resíduos sólidos (de $30 \%$ a $40 \%$ da pedra beneficiada), que hoje são armazenados nas indústrias ou encaminhados para aterros de resíduos industriais. Portanto, tecnologias devem ser desenvolvidas para a utilização desses resíduos (HARTMAN; SILVA; TONEZER, 2010).

Diversos autores estudaram a possibilidade de uso de solo-cimento como material componente de estacas escavadas $^{1}$ e afirmam que o solo-cimento é um material de grande potencialidade para ser aplicado em fundações para obras de pequeno porte (OKAMOTO; TAKANO; NAGAOKA, 1988; SILVA, 1994; SEGANTINI; CARVALHO, 1996; SEGANTINI, 2000). Foi afirmado que o uso de solo-cimento como substituto de concreto pode reduzir o custo com materiais e mão de obra na execução de estacas escavadas na ordem de $30 \%$ (SEGANTINI, 2000; $\quad$ CARVALHO; CORTOPASSI; CORTOPASSI JUNIOR, 1990). No entanto, não foi possível identificar trabalhos que utilizavam o resíduo da indústria de pedras preciosas, juntamente com solo e cimento, como material constituinte de estacas escavadas (do tipo brocas).

O objetivo do presente trabalho é apresentar um estudo em que se avaliou a viabilidade técnica e econômica do uso de resíduos industriais de pedras preciosas, em conjunto com solo-cimento, na confecção de estacas-broca para aplicação em habitações unifamiliares na região de Passo Fundo, RS.

\section{Materiais e método de pesquisa}

\section{Campo experimental de geotecnia}

Para o desenvolvimento da pesquisa utilizou-se o campo experimental do Centro de Tecnologia (Cetec), da Faculdade de Engenharia e Arquitetura (FEAR), pertencente à Universidade de Passo Fundo (UPF), localizado no Campus de Passo Fundo, junto à Rodovia Federal BR-285, Km 171, na cidade de Passo Fundo, região norte do estado do Rio Grande do Sul.

O solo escavado, que serviu de suporte para a execução das provas de carga, é do tipo residual, oriundo da decomposição de rochas basálticas (ígneas). O perfil do solo no local é homogêneo, devido à transição gradual entre os horizontes. A Figura 1 apresenta um resultado de ensaio SPT do campo experimental (LOPES JUNIOR, 2004). Do ponto de vista pedológico, o solo da região de Passo Fundo é caracterizado como um latossolo vermelho distrófico típico, pertencente à unidade Passo Fundo (STRECK et al., 2002).

\footnotetext{
${ }^{1}$ Estaca executada por perfuração do solo através de trado mecânico, sem emprego de revestimento ou fluido estabilizante, para que, em seguida, o furo seja preenchido com concreto, que é vertido a partir da superfície com o auxílio de um funil. Um caso particular da estaca escavada mecanicamente é a estacabroca, executada por perfuração, com trado manual, na maioria das vezes, e posterior concretagem mediante o lançamento do concreto a partir da superfície - NBR 6122 (ABNT, 2010).
} 


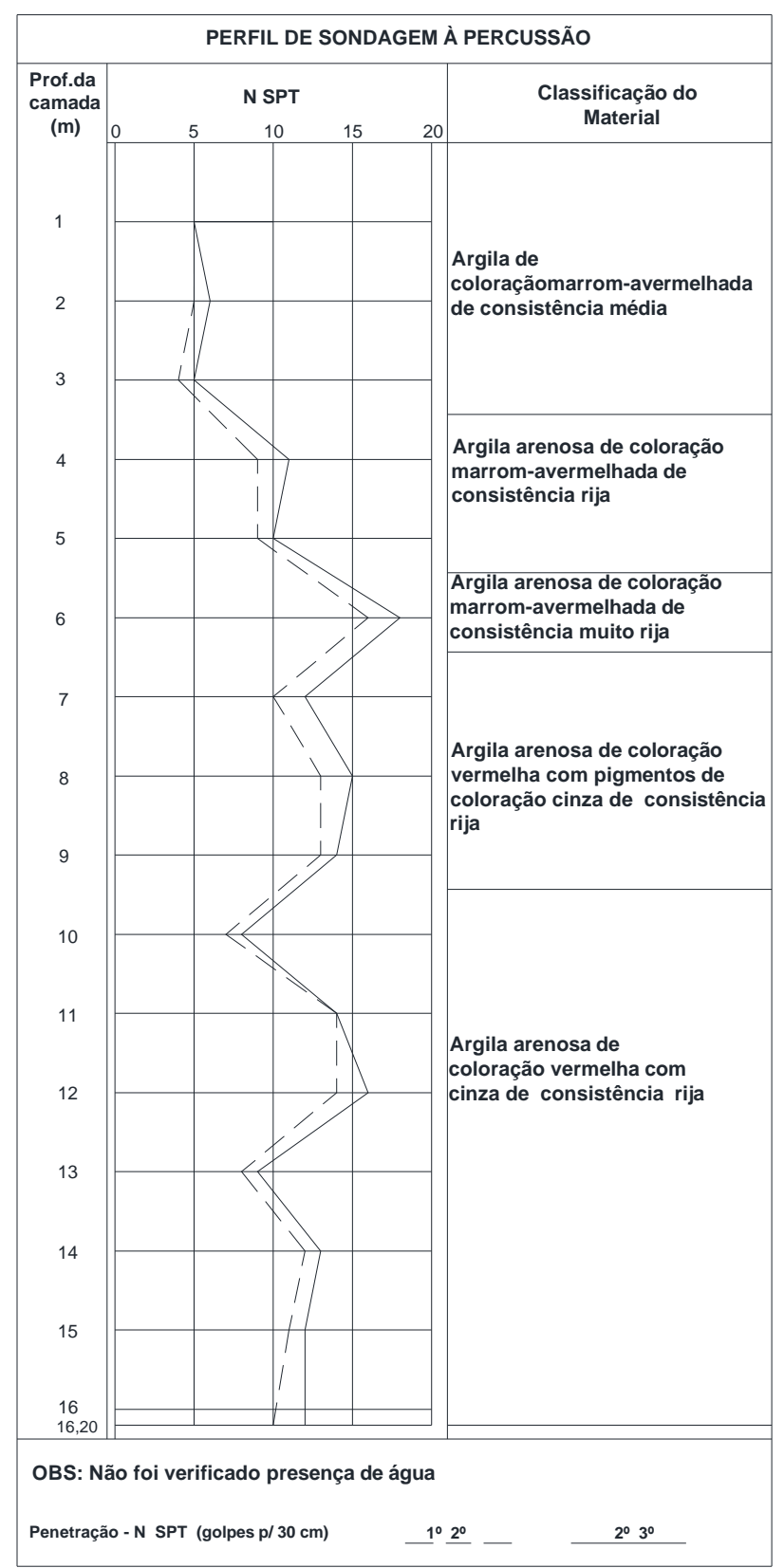

Figura 1 - Perfil de SPT do solo do campo experimental

Nota: adaptado de Lopes J unior (2004).

\section{Materiais}

Amostras deformadas do solo utilizado na pesquisa foram obtidas mediante coleta no Campo Experimental de Geotecnia da Universidade de Passo Fundo a uma profundidade de $1,50 \mathrm{~m}$. As propriedades físicas do solo estão descritas na Tabela 1.

O resíduo de beneficiamento de pedras preciosas é proveniente de indústrias do município de
Soledade, RS, distante $220 \mathrm{~km}$ da capital, Porto Alegre, e $70 \mathrm{~km}$ de Passo Fundo. O material é o resultado do processo de polimento de ágatas e ametistas. Também as propriedades físicas do resíduo estão descritas na Tabela 1 .

O material cimentante utilizado é o cimento Portland de alta resistência inicial (CP V-ARI) devido a seu ganho acelerado de resistência, atingindo aos 7 dias de idade cerca de $80 \%$ da resistência obtida aos 28 dias. 
Tabela 1 - Propriedades físicas do solo e do resíduo industrial

\begin{tabular}{lcc}
\hline \multicolumn{1}{c}{ Propriedade } & Solo & Resíduo \\
\hline Peso específico real das partículas $\left(\mathrm{kN} / \mathrm{m}^{3}\right)$ & 26,7 & 26,2 \\
Argila (\%) & 70 & 1,5 \\
Silte (\%) & 5 & 1,5 \\
Areia fina (\%) & 22 & 95 \\
Areia média (\%) & 3 & 2 \\
Limite de liquidez - LL (\%) & 53 & Não plástico \\
Limite de plasticidade - LP (\%) & 42 & Não plástico \\
Índice de plasticidade - IP (\%) & 11 & Não plástico \\
\hline
\end{tabular}

\section{Método de pesquisa}

A determinação do teor ótimo de cimento Portland para a mistura composta de solo e resíduo de beneficiamento de pedras preciosas foi realizada através do método físico-químico descrito por Casanova, Ceratti e Rodrigues (1992).

A quantidade do resíduo de beneficiamento de pedras preciosas foi determinada a partir do ensaio de resistência à compressão simples conforme os procedimentos da NBR 5739 (ABNT, 1994). O ensaio foi realizado em misturas com diferentes percentuais do resíduo $(25 \%, 50 \%$ e $75 \%)$.

Para determinar o peso específico aparente máximo $\left(\gamma \mathrm{d}_{\text {máx }}\right)$ e a umidade ótima $\left(\omega_{\text {ót }}\right)$ das misturas foram realizados ensaios de compactação na energia de Proctor Normal, conforme as orientações da NBR 12023 (ABNT, 1992).

A execução das cavas das três estacas escavadas foi realizada com o auxílio de um trado helicoidal mecanizado. As estacas ficaram com diâmetro de $0,23 \mathrm{~m}$ e profundidade de $3 \mathrm{~m}$ (Figura 2). A mistura proposta contendo o solo-cimento e o resíduo de beneficiamento de pedras preciosas (SCR) preencheu $2,50 \mathrm{~m}$ da escavação. Os $0,50 \mathrm{~m}$ finais foram compostos de concreto convencional (CC), a fim de evitar o rompimento da cabeça da estaca no decorrer das provas de carga estática. Não foi utilizada armadura.

Os procedimentos para a execução das estacas escavadas consistiram nas seguintes etapas:

(a) os materiais utilizados para a confecção de cada estaca foram pesados com precisão de 0,01 $\mathrm{kg}$. Em um recipiente o solo e o resíduo, depois de passados na peneira $\mathrm{n}^{\circ} 04$, foram misturados manualmente por $2 \mathrm{~min}$. Em seguida, foi acrescentado o cimento Portland, com mais $3 \mathrm{~min}$ de mistura. A fim de garantir a completa homogeneidade da mistura foi necessário destorroá-la manualmente;

(b) a determinação da umidade em campo foi realizada através do Método da Frigideira. Esse método foi adotado devido à necessidade de obtenção rápida do valor da umidade para correção antes da compactação das camadas;

(c) os 2,50 m compostos pela mistura de solocimento e resíduo foram executados em 10 camadas com espessura final apiloada de $25 \mathrm{~cm}$ (Figura 3). Para cada camada foi confeccionada uma nova mistura com a quantidade necessária de material;

(d) o concreto convencional, que teve por finalidade preencher os $0,50 \mathrm{~m}$ restantes de cada estaca, foi preparado no laboratório e posteriormente transportado ao destino. Para a mistura contou-se com o auxílio de uma betoneira de eixo inclinado com capacidade de 350 litros. $\mathrm{O}$ traço utilizado na produção do concreto foi obtido da pesquisa de Spadari (2008), ou seja, 1:2,06:2,94 (cimento:agregado miúdo:agregado graúdo), teor ideal de argamassa de $51 \%$ e relação água/cimento de 0,53;

(e) após a homogeneização do concreto retirou-se da betoneira material para moldagem de 3 corpos de prova, que foram rompidos aos 7 dias; e

(f) após o final de cada concretagem era feito o nivelamento das cabeças das estacas. 


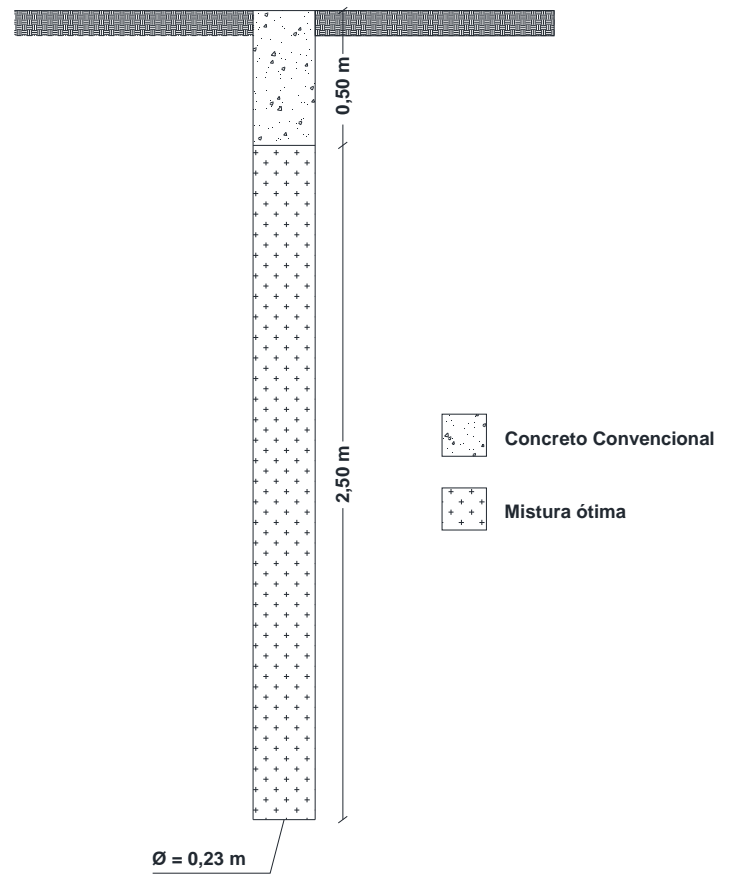

Figura 2 - Detalhamento da composição das estacas escavadas

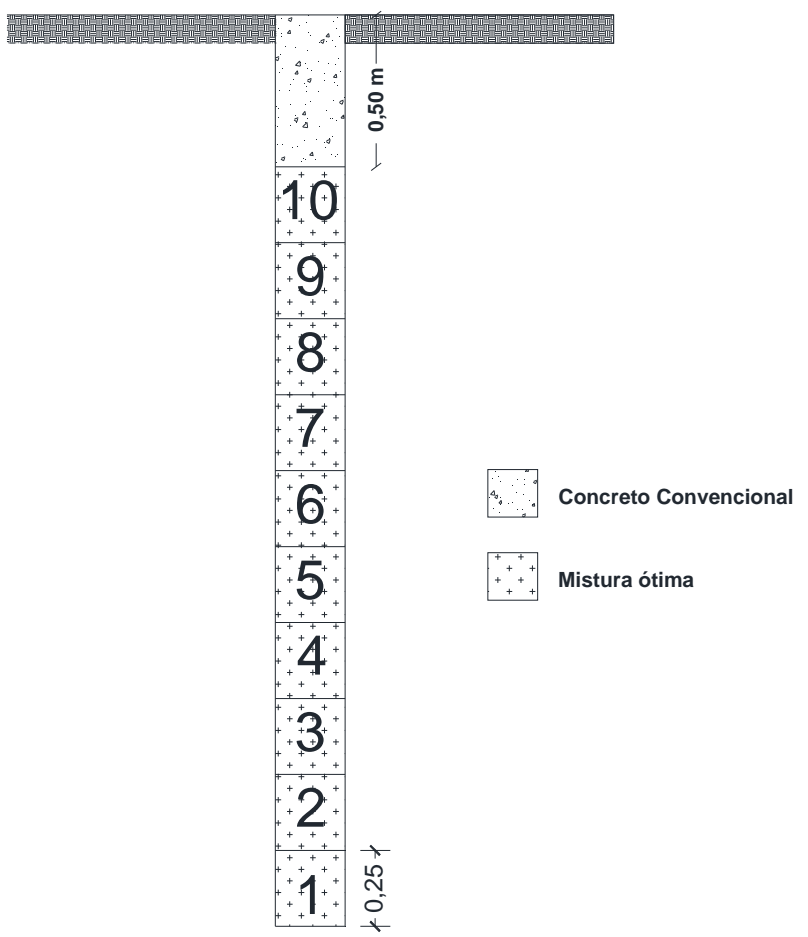

Figura 3 - Estaca executada em 10 camadas com espessura final apiloada de cada camada de $25 \mathrm{~cm}$

O croqui de localização destaca o sistema de reação, as estacas de concreto convencional executadas em pesquisa anterior e as estacas da mistura proposta no Campo Experimental de Geotecnia da UPF (Figura 4).

Para a realização das provas de carga nas estacas foram observadas as prescrições estabelecidas na norma NBR 12131 (ABNT, 2006), descritas a seguir:

(a) o carregamento foi realizado em estágios iguais e sucessivos, limitando-se o valor dos incrementos a no máximo $20 \%$ da carga de ruptura prevista para a estaca; 
(b) em cada estágio foi realizada leitura dos deslocamentos imediatamente após a aplicação da carga correspondente, seguindo-se as leituras decorridas $2 \mathrm{~min}, 4 \mathrm{~min}, 8 \mathrm{~min}, 15 \mathrm{~min}$ e $30 \mathrm{~min}$ contados a partir do início do estágio e posteriormente a cada $30 \mathrm{~min}$, até atingir a estabilização;

(c) a estabilização dos deslocamentos foi determinada através da avaliação do desempenho da curva tempo $x$ deslocamento, sendo admitida quando a diferença entre as leituras realizadas nos tempos $\mathrm{t}_{1}$ e $\mathrm{t}_{2}$ correspondeu a no máximo $5 \%$ do deslocamento total havido no mesmo estágio; e (d) o descarregamento foi feito de modo rápido, devido às limitações do equipamento.

Foi utilizado um pórtico como sistema de reação. Trata-se de um pórtico de aço, perfil $\mathrm{H}$, com 2,4 $\mathrm{mm}$ de espessura, suspenso sobre duas sapatas de concreto. A sobrecarga foi constituída por 11 blocos de $7 \mathrm{kN}$ cada, uma viga de $20 \mathrm{kN}$ e 2 sapatas de $20 \mathrm{kN}$ cada, totalizando aproximadamente $137 \mathrm{kN}$ de reação total (Figura 4). Obedeceu-se ao espaçamento mínimo entre as estacas e sistema de reação e estacas de 3 vezes o diâmetro das estacas $(0,69 \mathrm{~m})$.

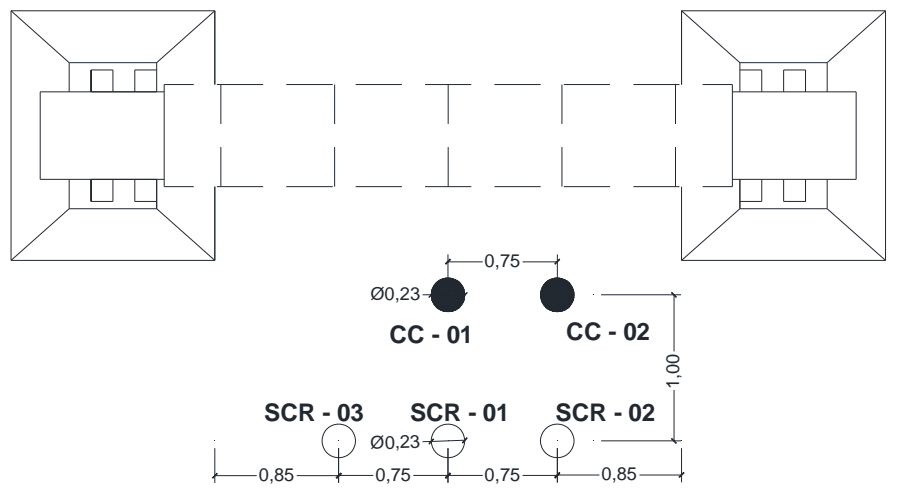

Estaca de Concreto Convencional (CC)

Estaca de Solo-Cimento e Resíduo (SCR)

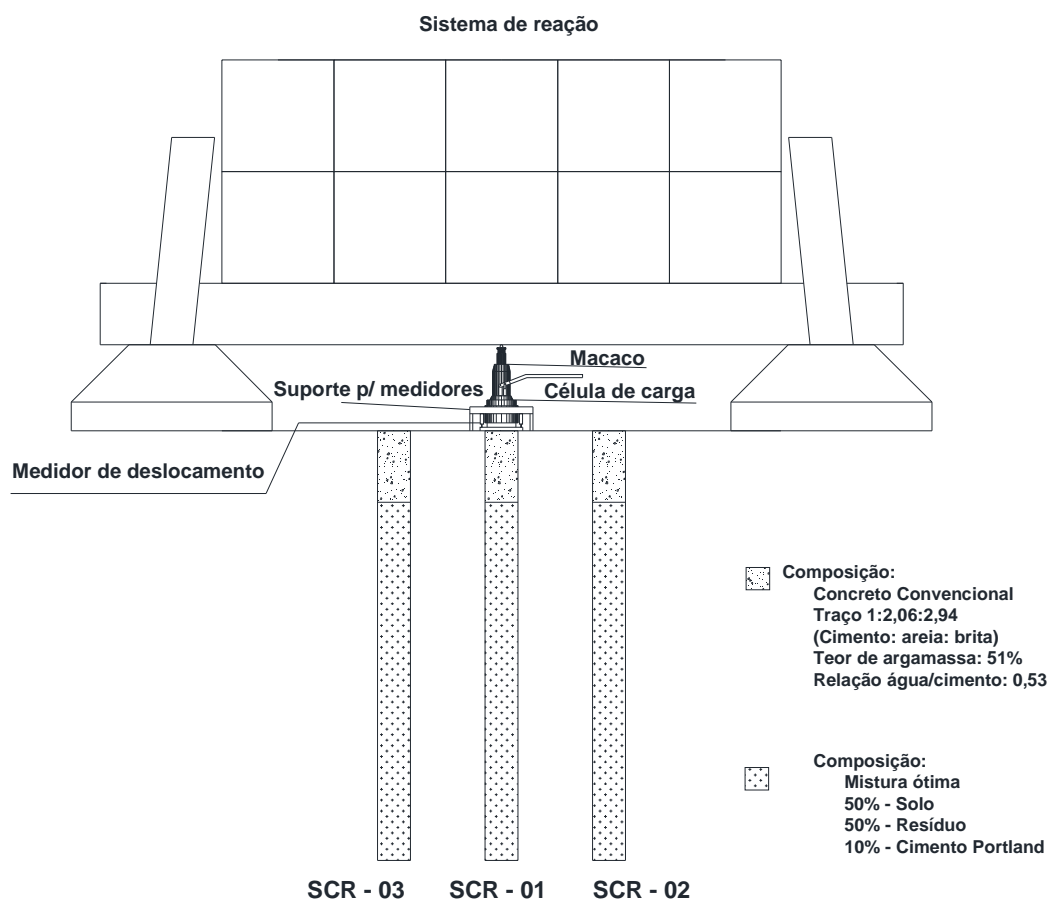

Figura 4 - Sistema de reação formado por duas sapatas, blocos de concreto e locação das estacas executadas com concreto convencional e as estacas de solo-cimento e resíduo e concreto convencional 
Para a transmissão de carga utilizou-se um macaco hidráulico com capacidade de carga de $250 \mathrm{kN}$ e uma célula de carga com capacidade para $500 \mathrm{kN}$ (erro máximo de $0,33 \%$ ).

O sistema foi montado sobre uma chapa de aço circular, a qual era assentada diretamente sobre a cabeça nivelada da estaca.

Os deslocamentos verticais foram medidos diretamente sobre as cabeças das estacas, com o auxílio de defletômetros digitais com precisão de $0,01 \mathrm{~mm}$, montados em dois pontos diametralmente opostos.

\section{Análise de custos}

Procedeu-se à análise de custos mediante a comparação de produção entre estacas escavadas convencionais e estacas escavadas compostas de solo-cimento e resíduo de beneficiamento de pedras preciosas. Os itens analisados nesta pesquisa foram: quantidade de materiais consumidos na execução; mão de obra; e transporte.

A determinação de custos foi efetuada a partir do Sistema Nacional de Pesquisa de Custos e Índices da Construção Civil (Sinapi), com o auxílio do software Planilha Eletrônica de Orçamento (Pleo).

\section{Apresentação e análise de resultados}

\section{Dosagem do solo-cimento}

Através do método físico-químico apresentado por Casanova, Ceratti e Rodrigues (1992) foi determinado o teor ótimo de cimento Portland para as misturas propostas no presente trabalho. Para garantir que ocorresse a cimentação e o ganho de resistência com o tempo, apesar de obter-se $7 \%$ de teor de cimento Portland, adotou-se o valor de $10 \%$ a ser adicionado à mistura de solo e resíduo.

\section{Determinação do teor de resíduo de beneficiamento de pedras preciosas}

A Tabela 2 apresenta os valores obtidos para a determinação do peso específico aparente seco e para a determinação da umidade ótima para as misturas contendo $25 \%, 50 \%$ e $75 \%$ de resíduo de beneficiamento de pedras preciosas (RBPP), com teor de cimento Portland de $10 \%$. A partir desses resultados observa-se que, com o aumento da quantidade de resíduo, há aumento da densidade e redução da umidade ótima. Essa variação ocorre porque o resíduo possui uma matriz mais arenosa, em comparação com o solo.

A Tabela 3 apresenta a variação da resistência à compressão simples de amostras das misturas contendo $25 \%, \quad 50 \%$ e $75 \%$ de resíduo de beneficiamento de pedras preciosas, com $10 \%$ de teor de cimento Portland, no período de 7 dias. Apesar de não oferecer o melhor desempenho em relação à resistência, a mistura composta de 50\% de resíduo e $50 \%$ de solo foi selecionada para a execução das estacas por questões puramente de cunho ambiental. O resíduo de beneficiamento de pedras preciosas causa maiores danos ambientais, se comparado ao solo; portanto, seu consumo em maior quantidade possibilita a retirada desse material do ambiente. Como a diferença de resistência entre as misturas contendo $25 \%$ e $50 \%$ de RBPP é de somente $6,25 \%$, foi possível essa tomada de decisão.

Tabela 2 - Peso específico aparente seco e umidade ótima para as misturas contendo $\mathbf{2 5 \%}$, $50 \%$ e $\mathbf{7 5 \%}$ de RBPP

\begin{tabular}{ccc}
\hline $\begin{array}{c}\text { Quantidade de RBPP } \\
(\%)\end{array}$ & $\begin{array}{c}\boldsymbol{\gamma} \mathbf{d}_{\text {máx }} \\
(\mathbf{k N} / \mathbf{m})\end{array}$ & $\begin{array}{c}\boldsymbol{\omega}_{\text {ót }} \\
(\mathbf{\%})\end{array}$ \\
\hline 25 & 16,1 & 20,6 \\
50 & 17,1 & 18,8 \\
75 & 17,4 & 18,4 \\
\hline
\end{tabular}

Tabela 3 - Variação do valor de RCS para misturas contendo $\mathbf{2 5} \%, \mathbf{5 0} \%$ e $\mathbf{7 5} \%$ de RBPP

\begin{tabular}{cccc}
\hline Resíduo (\%) & $\begin{array}{c}\text { Valor médio de } \\
\text { RCS (MPa) }\end{array}$ & $\begin{array}{c}\text { Desvio padrão } \\
\text { (MPa) }\end{array}$ & $\begin{array}{c}\text { Coeficiente de } \\
\text { variação (\%) }\end{array}$ \\
\hline 25 & 5,11 & 0,76 & 14,87 \\
50 & 4,79 & 0,68 & 14,20 \\
75 & 3,62 & 0,30 & 8,29 \\
\hline
\end{tabular}




\section{Provas de carga}

Na Figura 5 estão apresentadas as curvas carga $\mathrm{x}$ deslocamento das estacas ensaiadas de solocimento e resíduo, onde se verifica que a dispersão dos resultados é pequena. Todas as 3 estacas apresentaram comportamento linear até atingirem a carga de aproximadamente $70 \mathrm{kN}$. Após esse valor os deslocamentos tenderam a aumentar significativamente com o incremento de carga. Os valores de recalque para a carga de $70 \mathrm{kN}$ variaram de $4 \mathrm{~mm}$ a $7 \mathrm{~mm}$, valores estes considerados aceitáveis para estacas na prática de engenharia.

\section{Comparação entre a resistência à compressão da mistura proposta das estacas de concreto convencional}

A Figura 6 apresenta as curvas carga $\mathrm{x}$ deslocamento das estacas da mistura proposta juntamente com as curvas das estacas de concreto convencional, executadas por Spadari (2008).

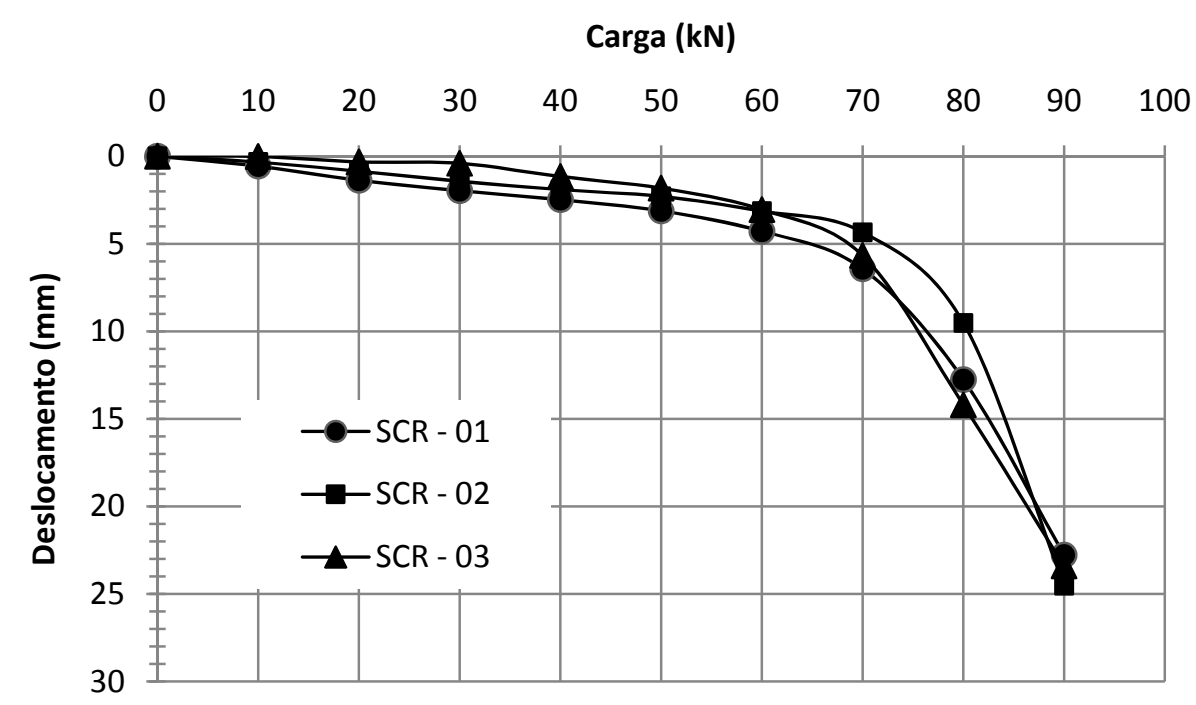

Figura 5 - Curvas carga $\mathrm{x}$ deslocamento das estacas ensaiadas

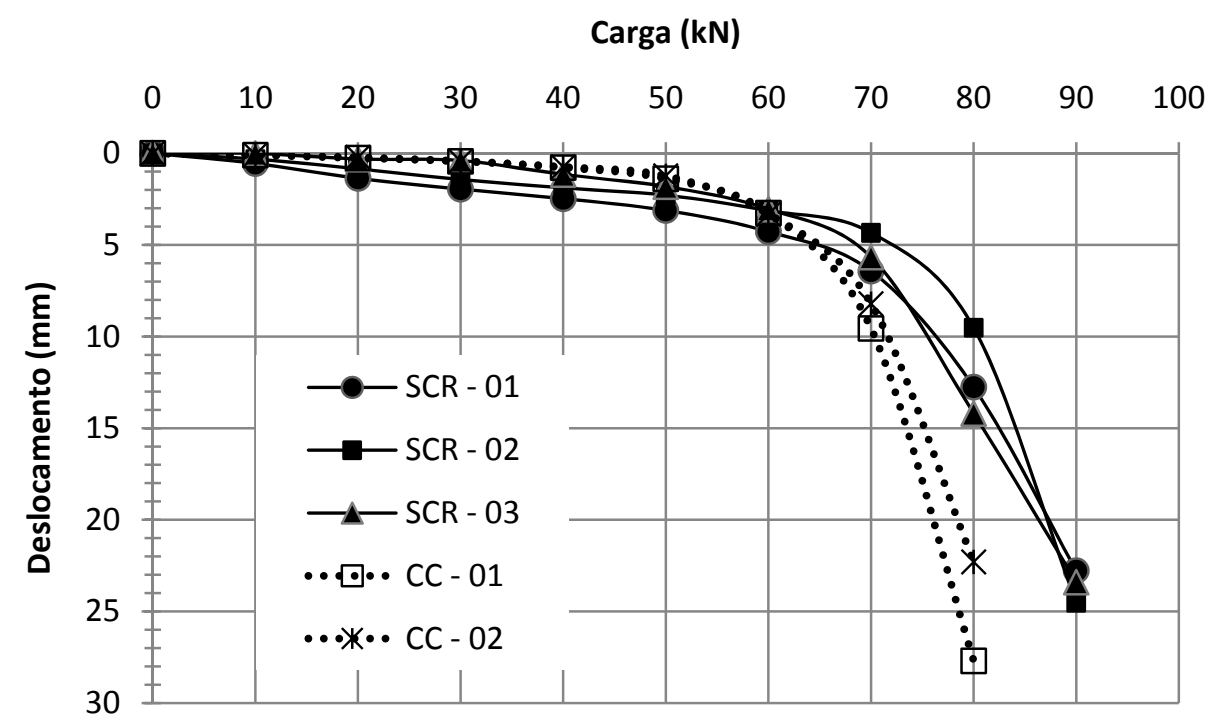

Figura 6 - Comparação entre as estacas de solo-cimento e resíduo e as estacas de concreto convencional 
Ao comparar qualitativamente os resultados das estacas com o material proposto e as estacas de concreto convencional é possível verificar que as estacas de solo-cimento e resíduo de beneficiamento de pedras preciosas apresentaram comportamento muito semelhante às estacas de concreto convencional. Uma pequena dispersão ocorre após o trecho linear da curva, onde as estacas de solo-cimento e resíduo apresentam um ganho de carga maior para um mesmo incremento de recalque. A hipótese levantada para explicar essa diferença de comportamento está ligada ao processo executivo. No caso da estaca de solocimento e resíduo, pelo fato de o solo ser compactado ao longo do fuste, ocorre aumento da rugosidade e, com isso, sua capacidade de carga. Também, o processo de compactação das primeiras camadas pode ter compactado o solo natural da ponta, o que ocasionou maior capacidade de carga de ponta. No entanto, do ponto de vista prático, essa diferença não chega a ser significativa.

Para definir a carga de ruptura foi adotado um critério de recalque, ou seja, a carga de ruptura é aquela correspondente ao valor de recalque correspondente ao diâmetro da estaca dividido por $30(\mathrm{D} / 30)$. Esse método é também conhecido como Método Britânico, descrito pelo British Standard Code BS 8004 (1986) ${ }^{2}$ e apresentado em Milititsky (1991). Não foi possível utilizar o método sugerido pela NBR 6122 (ABNT, 2010) devido a não ter disponível o módulo de elasticidade dos materiais. No entanto, a adoção desse método não altera a análise dos resultados. Admitindo, portanto, que a carga de ruptura é aquela correspondente ao recalque de $23 \mathrm{~mm}$, as estacas convencionais apresentam valor de $76 \mathrm{kN}$, enquanto as estacas com a mistura proposta a carga de ruptura obtida, $87 \mathrm{kN}$ para o mesmo recalque. Considerando um fator de segurança global igual a 2, conforme a NBR 6122 (ABNT, 2010), pode-se dizer que tanto as estacas de concreto convencional quanto as da mistura de solo-cimento e resíduo apresentam carga admissível de $38 \mathrm{kN}$ e $43 \mathrm{kN}$ respectivamente. A diferença de valores é de $5 \mathrm{kN}$, ou seja, $13 \%$. Esses valores, do ponto de vista de prática de engenharia de fundações, são considerados praticamente iguais, podendo-se afirmar que o comportamento das estacas não foi influenciado pelo tipo de material constituinte. Outro ponto que reforça esta análise é que os recalques para a carga admissível variam de $1 \mathrm{~mm}$ a $3 \mathrm{~mm}$ para todas as estacas ensaiadas. Esses valores são adequados para a prática da engenharia de fundações. Em outras palavras, o uso de estacas de concreto convencional ou de estaca de mistura de solo-cimento e resíduo leva ao mesmo comportamento mecânico se fossem utilizadas em habitações unifamiliares.

\section{Análise de custos}

A Tabela 4 apresenta o custo dos materiais e mão de obra da estaca convencional e da estaca de mistura de solo-cimento e resíduo (com 0,50 m de concreto). Verifica-se que o custo final de uma estaca escavada produzida com solo-cimento e resíduo é inferior ao custo de uma estaca escavada composta de concreto convencional. Com base nos resultados observa-se que essa diferença ocorre devido basicamente ao custo inferior do cimento Portland, utilizado na produção da estaca proposta ( $50 \%$ do custo da estaca convencional), pois esse elemento é substituído parcialmente pelo solo e resíduo. Também, o fato de ser dispensável o uso de agregados contribui para essa redução de custos. A estaca de solo-cimento tem custo um pouco superior na mão de obra, devido ao maior tempo necessário para sua execução, devido à compactação das camadas. No entanto, de maneira global, a redução de custo de uma estaca de solocimento e resíduo é de $38 \%$ quando comparada com a produção de uma estaca convencional.

Tabela 4 - Comparativo de custo das estacas de concreto convencional e de solo-cimento resíduo (material e mão de obra)

\begin{tabular}{lcc}
\hline & $\begin{array}{c}\text { Concreto } \\
\text { convencional (3 m) }\end{array}$ & $\begin{array}{c}\text { Solo-cimento e resíduo (2,5 m) e } \\
\text { concreto convencional (0,5 m) }\end{array}$ \\
\hline Material & $\mathrm{R} \$ 20,25$ & $\mathrm{R} \$ 9,92$ \\
Cimento & $\mathrm{R} \$ 6,00$ & $\mathrm{R} \$ 1,00$ \\
Brita & $\mathrm{R} \$ 5,73$ & $\mathrm{R} \$ 0,96$ \\
Areia & -- & $\mathrm{R} \$ 0,28$ \\
Resíduo (transporte) & $\mathrm{R} \$ 16,80$ & $\mathrm{R} \$ 18,10$ \\
\hline Mão de obra & $\mathrm{R} \$ 48,78$ & $\mathrm{R} \$ 30,26$ \\
Pedreiro e servente & & \\
\hline TOTAL &
\end{tabular}

${ }^{2}$ BRITISH STANDARDS INSTITUTION. BS 8004: code of practice for foundations. London, 1986. $160 \mathrm{p.}$ 


\section{Considerações finais}

Este trabalho avaliou a possibilidade de utilização de estacas escavadas de solo-cimento e resíduo de beneficiamento de pedras em habitação unifamiliar, em substituição de estacas de concreto convencional. Com base nos resultados obtidos foi possível chegar às seguintes conclusões:

(a) a mistura adotada que atende às características de resistência e trabalhabilidade foi aquela contendo $50 \%$ de resíduo de beneficiamento de pedras preciosas e $50 \%$ de solo, com $10 \%$ de teor de cimento em relação ao peso seco dos materiais;

(b) apesar da diferença dos materiais utilizados na execução das estacas ensaiadas nesta pesquisa e às executadas com concreto convencional, verificouse semelhança no comportamento das curvas carga $\mathrm{x}$ deslocamento e nos valores de carga admissível, indicando que o material constituinte das estacas não é o que controla a capacidade de carga, e sim o solo local ao redor da estaca;

(c) o custo final de uma estaca escavada produzida com solo-cimento e resíduo (com 0,50 $\mathrm{m}$ de concreto convencional) é $38 \%$ inferior ao custo de uma estaca escavada composta de concreto convencional; e

(d) o emprego da mistura de solo-cimento e resíduo de beneficiamento de pedras preciosas em estacas escavadas moldadas in loco é técnica e economicamente viável, podendo ser empregada em fundações de residências unifamiliares.

\section{Referências}

ASSOCIAÇÃO BRASILEIRA DE NORMAS TÉCNICAS. NBR 5739: ensaio de compressão de corpos-de-prova cilíndricos. Rio de Janeiro, 1994.

ASSOCIAÇÃO BRASILEIRA DE NORMAS TÉCNICAS. NBR 6122: projeto e execução de fundações. Rio de Janeiro, 2010.

ASSOCIAÇÃO BRASILEIRA DE NORMAS TÉCNICAS. NBR 12023: solo-cimento: ensaio de compactação. Rio de Janeiro, 1992.

ASSOCIAÇÃO BRASILEIRA DE NORMAS TÉCNICAS. NBR 12131: estacas: prova de carga estática. Rio de Janeiro, 2006.

CÂMARA BRASILEIRA DA INDÚSTRIA DA CONSTRUÇÃO. Anuário. Disponível em: $<$ http://www.cbicdados.com.br/anuario.asp $>$. Acesso em: 10 mar. 2011.
CARVALHO, J.; CORTOPASSI, R. S.; CORTOPASSI JUNIOR, R. S. Análise do Comportamento do Solo-Cimento Plástico Para Uso em Fundações. In: CONGRESSO BRASILEIRO DE MECÂNICA DOS SOLOS E ENGENHARIA DE FUNDAÇÕES, 9., Salvador, 1990. Anais... Salvador, BA: ABMS, 1990. v. 2, p. 403-408.

CASANOVA, F. J.; CERATTI, J. A. P.; RODRIGUES, M. G. M. Procedimento Para a Dosagem Físico-Química do Solo-Cimento. In: REUNIÃO ANUAL DE PAVIMENTAÇÃO, Sergipe; Aracaju, 1992. Anais... Sergipe; Aracaju, 1992. p. 82-86.

GONZALES, M. A. S.; RAMIRES, M. V. V. Análise de Gestão dos Resíduos Gerados Dentro dos Canteiros de Obras. In: SIMPÓSIO BRASILEIRO DE GESTÃO E ECONOMIA DA CONSTRUÇÃO, 4.; ENCONTRO LATINOAMERICANO DE GESTIÃO E ECONOMIA DA CONSTRUÇÃO, 1., Porto Alegre, 2005. Anais... Porto Alegre: ANTAC, 2005.

HARTMANN, L. A.; SILVA, J.; TONEZER, D. A. Tecnologias Para o Setor de Gemas, Jóias e Mineração. Porto Alegre: IGEO/UFRGS, 2010. $320 \mathrm{p}$.

LOPES JUNIOR, L. Provas de Carga Estática em Estacas. 73 f. 2004. Trabalho de Conclusão de Curso (Graduação em Engenharia Civil) Faculdade de Engenharia e Arquitetura, Universidade de Passo Fundo, Passo Fundo, 2004.

MILITITSKY, J. Provas de Carga Estáticas. In: SEMINÁRIO DE FUNDAÇÕES ESPECIAIS, 2., São Paulo, 1991. Anais... São Paulo: ABMS/ABEF, 1991. v. 2, p. 203-208.

OKAMOTO, T.; TAKANO, K.; NAGAOKA, H. A New Pile Foundation Composed of Soil Cement and Steel Pipe. In: DEEP FOUNDATION ON BORED AND AUGER PILES, Rotterdam, 1988. Proceedings... Rotterdam, 1988. p. 371-376.

ÖSTRÖM, C. S.; BAKENS, W. CIB Agenda 21 for Sustainable Construction: why, how and what? Building Research and Information, v. 27, n. 6, p. 348-354, 1999.

SCHNEIDER, D. M.; PHILIPPI JUNIOR, A. Public Management of Construction and Demolition Waste in the City of São Paulo. Ambiente Construído, Porto Alegre, v. 4, n. 4, out./dez. 2004. 
SEGANTINI, A. A. S.; CARVALHO, D. Provas de Carga em Estacas Moldadas "in loco" de SoloCimento Plástico no Solo Colapsível de Ilha Solteira. In: SEMINÁRIO DE FUNDAÇÕES ESPECIAIS E GEOTECNIA, 3., São Paulo, 1996. Anais... São Paulo: ABMS/ABEF, 1996. v. 2, p. 111-122.

SEGANTINI, A. A. S. Utilização de SoloCimento Plástico em Estacas Escavadas Com Trado Mecânico em Ilha Solteira (SP). 176 f. Campinas, 2000. Tese (Doutorado em Engenharia Civil) - Escola de Engenharia, Universidade Estadual de Campinas, Campinas, 2000.

SILVA, M. T. Interação Solo-Estrutura de Fundação em Estacas de Solo-Cimento e Concreto. 101 f. Brasília, DF, 1994. Dissertação (Mestrado em Engenharia Civil) - Faculdade de Tecnologia, Universidade, Universidade de Brasília, DF, 1994.
SPADARI, G. Capacidade de Carga de Estacas Com Agregado de Resíduo da Construção e Demolição. 80 f. 2008. Trabalho de Conclusão de Curso (Graduação em Engenharia Civil) -

Faculdade de Engenharia e Arquitetura, Universidade de Passo Fundo, Passo Fundo, 2008.

STRECK, E. V. et al. Solos do Rio Grande do Sul. Porto Alegre: Editora da UFRGS, 2002. 126 p.

WOOLEY, T. et al. Green Building Handbook. London: E\&FN Spon, 1997.

\section{Revista Ambiente Construído}

Associação Nacional de Tecnologia do Ambiente Construído

Av. Osvaldo Aranha, 99 - 3o andar, Centro

Porto Alegre - RS - Brasil

CEP 90035-190

Telefone: +55 (51) 3308-4084

Fax: +55 (51) 3308-4054

www. seer. ufrgs. br/ ambienteconstruido

E-mail: ambienteconstruido@ufrgs.br 